\title{
VIGAS DE CONCRETO ARMADO REFORÇADAS POR MEIO DE ENCAMISAMENTO
}

\section{REINFORCED CONCRETE BEAMS STRENGTHENED USING JACKETING USING JACKETING}

\author{
Paula Miranda da Silva ${ }^{1}$, Andréa Prado Abreu Reis Liserre ${ }^{2}$, Áureo Ferreira da Silva ${ }^{3}$
}

Recebido em 27 de outubro de 2012; recebido para revisão em 01 de novembro de 2012; aceito em 03 de novembro de 2012; disponivel on-line em 06 de novembro de 2012.

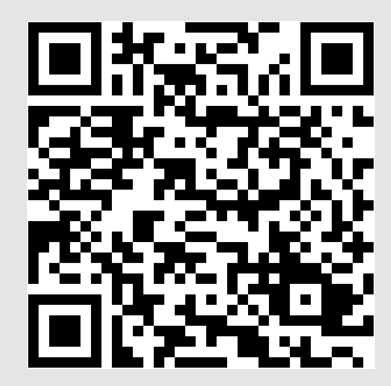

PALAVRAS CHAVES:

Vigas;

Peças compostas;

Flexão;

Reforço;

Conectores de

cisalhamento.

* Contato com os autores:

${ }^{1}$ e-mail : paulaengenheira@hotmail.com (P. M. da Silva)

Mestre em Engenharia Civil pelo Curso de Mestrado em Engenharia Civil da Escola de Engenharia Civil da Universidade Federal de Goiás

22e-mail : andrea.liserre@gmail.com (A. P. A. R. Liserre)

Professora Dsc. da Escola de Engenharia Civil - Universidade Federal de Goiás (EEC/UFG)

${ }^{3}$ e-mail : aureo.ferreira@ig.com.br (A. F. da Silva)

Mestrando do Curso de Mestrado em Engenharia Civil - Escola de Engenharia Civil - Universidade Federal de Goiás (CMEC-EEC-UFG) 


\section{INTRODUÇÃO}

Toda estrutura deve ser executada para ter desempenho satisfatório conforme as finalidades de uso para a qual foi projetada. A NBR 6118:2003, em seu item 6.1, explicita que as estruturas de concreto devem ser projetadas e construídas para que, sob as condições ambientais previstas na época do projeto, e quando utilizadas conforme preconizado em projeto, as mesmas conservem sua segurança, estabilidade e aptidão em serviço durante o período correspondente à sua vida útil. Entretanto, mesmo o concreto sendo considerado um material durável, em alguns casos ocorre problemas patológicos que deterioram as estruturas. As causas da deterioração são as mais diversas: envelhecimento natural da estrutura, falhas involuntárias e casos de imperícia, erros de execução, erros de projeto, utilização inadequada, entre outros fatores.

O estágio em que cada edificação, em função do grau de deterioração, atinge níveis de desempenho insatisfatório varia de acordo com o tipo de estrutura. Algumas delas, por falhas de projeto ou de execução, já iniciam suas vidas úteis de forma insatisfatória, enquanto outras chegam ao final ainda mostrando um bom desempenho. Por outro lado, o fato de uma estrutura apresentar-se com desempenho insatisfatório não significa que ela esteja necessariamente condenada. A avaliação desta situação é, talvez, o objetivo maior da Patologia das Construções, posto que essa seja a ocasião que requer imediata intervenção técnica, de forma que ainda seja possível reabilitar a estrutura.

A NBR 6118 (2003), em seu item 25.3, indica que se for constatada alguma não-conformidade de parte ou do todo da estrutura, o engenheiro responsável pela obra deve avaliar a situação e adotar uma das seguintes alternativas: determinar as restrições de uso da estrutura; providenciar o projeto de reforço ou decidir pela demolição parcial ou total da estrutura. Contudo, devido às particularidades presentes em cada problema patológico detectado, e em cada estrutura construída, ainda não há uma normalização técnica destinada exclusivamente ao projeto e execução de reforço de estruturas de concreto armado no Brasil. Isso faz com que os engenheiros responsáveis pelo projeto de um reforço estrutural ainda utilizem técnicas baseadas na experiência empírica acumulada, pois não existe uma metodologia de análise do comportamento estrutural de peças reabilitadas, nem diretrizes que orientem 0 projetista durante o processo de redimensionamento e reprojeto.

Existem várias técnicas de reabilitação de estruturas de concreto armado, dentre elas pode-se citar: a protensão externa, a adição de chapas ou perfis metálicos, o uso de materiais compósitos tais como fibras de carbono, a adição de concreto com ou sem aço à seção transversal do elemento, dentre outras. Essa última técnica, também conhecida por encamisamento da seção, é relativamente simples, pois usa os materiais mais comuns da construção civil, que são o aço e o concreto. Isso faz com que o custo da reabilitação seja bastante competitivo quando comparado a outras técnicas de reabilitação estrutural, sendo uma das mais utilizada no Brasil. Apesar disso, ainda existem vários fatores que merecem ser investigados para avaliar melhor o comportamento de elementos estruturais reabilitados usando este tipo de intervenção. No caso do reforço de vigas por encamisamento, geralmente adiciona-se uma nova camada de concreto com ou sem barras de aço na face tracionada ou na face comprimida, logo o reforço envolverá apenas parcialmente a seção original da estrutura existente. Entretanto, nada impede que o encamisamento seja feita em todo o contorno do elemento estrutural (encamisamento total). A Figura 1 ilustra fotos de vigas reforçadas pela técnica do encamisamento.

Vigas reforçadas por encamisamento são, na verdade, peças compostas, pois são formadas pelo contato entre dois concretos moldados em idades diferentes, e que possuem características distintas. Quando se reforça um elemento estrutural usando esta técnica, uma das maiores preocupações é garantir uma aderência adequada entre o reforço (concreto novo) e o concreto original da peça (substrato) para evitar o deslizamento entre as partes, só assim a peça irá trabalhar monoliticamente. Um recurso muito utilizado para garantir a monoliticidade é a adoção de pinos que atravessam a interface dos dois concretos, os quais passam a resistir aos esforços de cisalhamento que ali se desenvolvem. Esses pinos podem ser representados por estribos prolongados, chumbadores, ou pequenas barras coladas com resinas (Figura 2).

Apesar desta técnica ser bastante utilizada, ainda há lacunas de conhecimento no que se refere ao conhecimento do comportamento de peças reforçadas por esta técnica em relação, por exemplo, a forma de determinar a quatidade de aço da armadura de costura. Diante deste cenário, estabeleceu-se como objetivo principal deste trabalho, a avaliação do comportamento de vigas de concreto armado reforçadas por adição de uma camada de concreto à face comprimida, usando conectores de cisalhamento para melhorar a aderência entre o concreto antigo (substrato) e o novo concreto adicionado. Para isso, foram analisados os seguintes parâmetros: 
- influência do tipo de conector de cisalhamento na aderência entre concretos moldados em idades distintas;

- influência da taxa de conectores de cisalhamento posicionados ao longo da junta, na aderência entre os concretos do substrato e do reforço;

- influência do nível de pré-fissuração existente antes da execução do reforço no comportamento final da peça reabilitada;

- influência de uma armadura de confinamento na região do reforço.

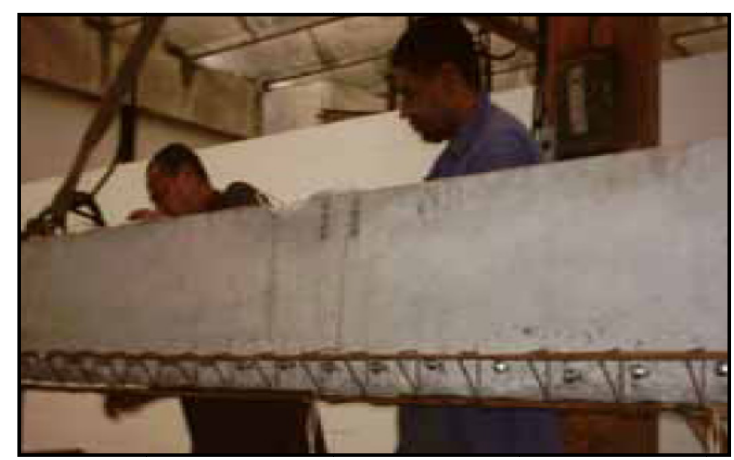

(a) Viga reforçada apenas na região tracionada. Fonte: SANTOS, E.W.F. (2006).

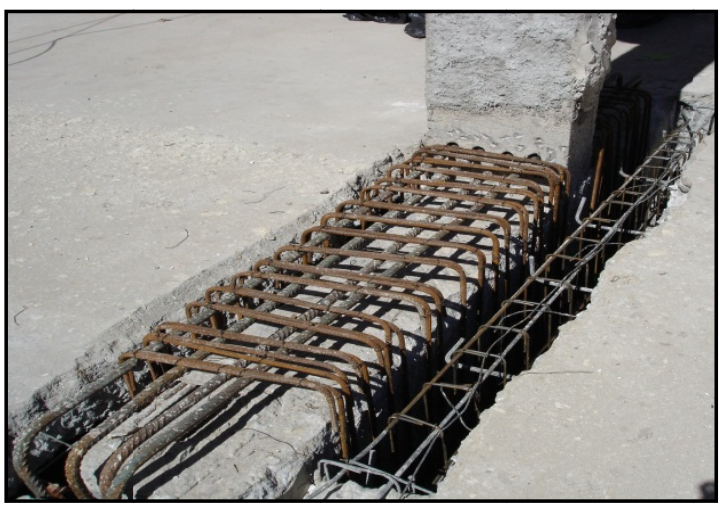

(b) Viga reforçada em todo contorno (encamisamento total).

Figura 1: Fotos de vigas reforçadas por encamisamento parcial e encamisamento total.

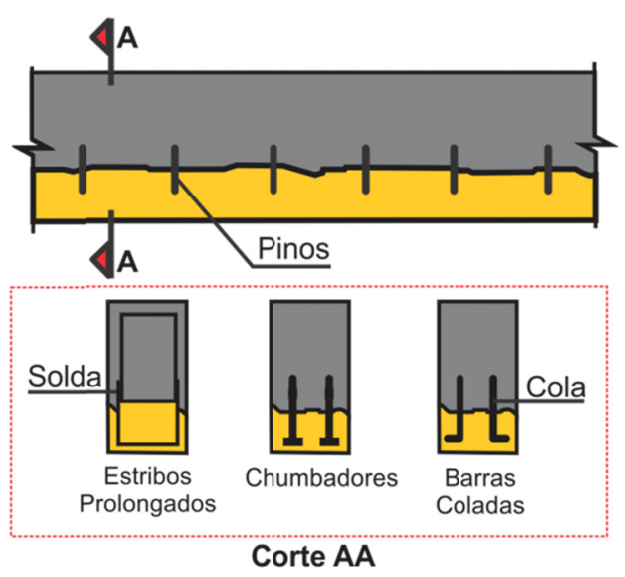

Figura 2: Pinos de ligação entre concretos. Fonte: (Piancastelli, 2005).

\section{PROGRAMA EXPERIMENTAL}

O programa experimental desenvolvido foi composto por duas séries de ensaios, no qual se levou à ruptura um total de onze vigas retangulares biapoiadas de concreto armado, sendo duas monolíticas e nove reforçadas. A nomenclatura e as principais características dessas vigas encontram-se na Tabela 1.

As vigas possuíam comprimento de $2000 \mathrm{~mm}$, vão teórico de $1800 \mathrm{~mm}$ e seção transversal com largura de $120 \mathrm{~mm}$. Nas vigas monolíticas, a altura da seção transversal dependia do tipo de peça de referência que representavam. No caso da viga monolítica de referência que representava a estrutura antes do reforço, a altura era de $250 \mathrm{~mm}$. Já para a viga monolítica de referência que representava a peça após o reforço, a altura era de $400 \mathrm{~mm}$. Todas vigas a serem reforçadas possuíam altura de $250 \mathrm{~mm}$ antes da intervenção e, após o reforço, a altura passava para $400 \mathrm{~mm}$, pois se acrescentava uma camada de $150 \mathrm{~mm}$ de concreto à face comprimida.

Todas as vigas possuíam armadura longitudinal tracionada composta por duas barras de $16 \mathrm{~mm}$ de diâmetro, armadura transversal composta por estribos de dois ramos de $6.3 \mathrm{~mm}$ de diâmetro espaçados a cada $125 \mathrm{~mm}$, e porta-estribos de $5.0 \mathrm{~mm}$ de diâmetro. Nas vigas VRI3, VRAF3, VRI1B, VRI1C, VRI2B e VRI2C foram colocadas armaduras de confinamento na camada de $150 \mathrm{~mm}$ onde seria adicionado o concreto do reforço. $\mathrm{Na}$ viga reforçada com conector " $U$ " invertido (VRU3) não se usou armadura de confinamento, pois essa função já era exercida pelo próprio conector devido à geometria deste. Esta armadura também não foi usada nas vigas VRI1A e VRI2A a fim de se avaliar a real influência desta armadura na resistência final da peça. A Figura 3 apresenta as seções transversais e os detalhes das armaduras das vigas ensaiadas.

$\mathrm{Na} 1^{\text {a }}$ série, foram ensaiadas duas vigas monolíticas de referência (VM25 e VM40) e três vigas reforçadas (VRI3, VRU3 e VRAF3) que se diferenciavam apenas em função do tipo de conector de cisalhamento usado. Com estes ensaios se analisou a influência do tipo do conector na aderência entre os concretos do substrato e do reforço. Os três tipos de conectores usados respectivamente nas vigas VRI3, VRU3 e VRAF3 tinham as seguintes características: os do tipo "I" e " $U$ " invertido eram formados por barra de aço nervurada CA50, e o do tipo "AF" era um parafuso de expansão mecânica do tipo "parabolt" da marca Âncora Sistemas de Fixação, com diâmetro de $8.0 \mathrm{~mm}$, do mesmo tipo dos usados por Sahb (2008) e Risso (2008).

Para avaliar a eficiência destes conectores na resistência ao cisalhamento da junta formada entre o concreto do substrato e do reforço, utilizou-se a mesma 
área de aço de conectores $\left(\mathrm{a}_{\mathrm{sc}}=5 \mathrm{~cm}^{2} / \mathrm{m}\right)$ nas três vigas reforçadas da 1 a série. As características desses conectores estão na Tabela 2, e a Figura 4 apresenta fotos destes dispositivos.

\begin{tabular}{|c|c|c|}
\hline Série & Viga & Descrição \\
\hline \multirow{5}{*}{1 a } & VM $25^{*}$ & Viga monolítica de seção 120 mm x 250 mm, não fissurada \\
\hline & VM40* & Viga monolítica de seção 120 mm x 400 mm, não fissurada \\
\hline & $\mathrm{VRI}^{*}$ & Viga reforçada com conector "I", $\mathrm{a}_{\mathrm{sc}}=5,00 \mathrm{~cm}^{2} / \mathrm{m}$, com armadura de confinamento, não fissurada \\
\hline & VRU3 $^{*}$ & Viga reforçada com conector " $\mathrm{U}$ ", $\mathrm{a}_{\mathrm{sc}}=5,00 \mathrm{~cm}^{2} / \mathrm{m}$, com armadura de confinamento, não fissurada \\
\hline & VRAF3 $^{*}$ & Viga reforçada com conector "AF", $\mathrm{a}_{\mathrm{sc}}=5,00 \mathrm{~cm}{ }^{2} / \mathrm{m}$, com armadura de confinamento, não fissurada. \\
\hline \multirow{6}{*}{$2^{\mathrm{a}}$} & VRI1A ${ }^{*}$ & Viga reforçada sem conector sem armadura de confinamento, não fissurada \\
\hline & VRI1B ${ }^{*}$ & Viga reforçada sem conector com armadura de confinamento, fissurada \\
\hline & VRI1C ${ }^{* *}$ & Viga reforçada sem conectores com armadura de confinamento, fissurada. \\
\hline & VRI2A ${ }^{*}$ & Viga reforçada com conectores, $a_{s c}=1,25 \mathrm{~cm}^{2} / \mathrm{m}$, sem armadura de confinamento, não fissurada \\
\hline & VRI2B ${ }^{*}$ & Viga reforçada com conectores, $\mathrm{a}_{\mathrm{sc}}=1,25 \mathrm{~cm}^{2} / \mathrm{m}$, com armadura de confinamento, fissurada. \\
\hline & VRI2C $C^{* *}$ & Viga reforçada com conectores, $a_{\mathrm{sc}}=1,25 \mathrm{~cm}^{2} / \mathrm{m}$, com armadura de confinamento, fissurada. \\
\hline \multicolumn{3}{|c|}{$\begin{array}{l}\text { Obs.: } \\
\text { * : Vigas ensaiadas usando o esquema estático tipo "a" ilustrado na Figura 1.a } \\
\text { ** : Vigas ensaiadas usando o esquema estático tipo "b" ilustrado na Figura 1.b } \\
a_{\mathrm{sc}} \text { : área de aço de conectores de cisalhamento. }\end{array}$} \\
\hline
\end{tabular}

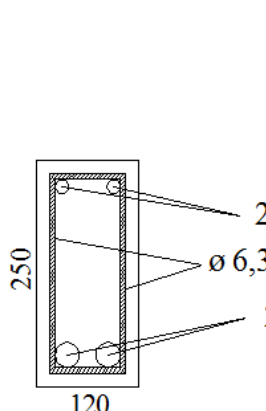

(a)

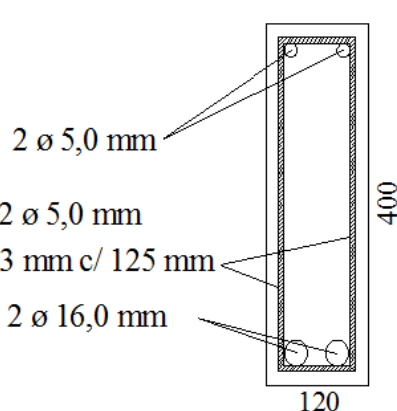

(b)

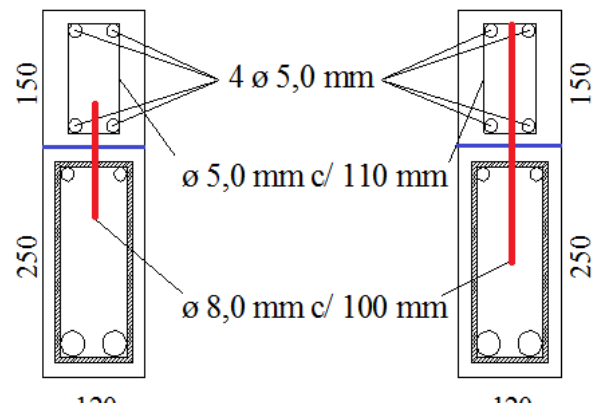

120

(c)

(d)

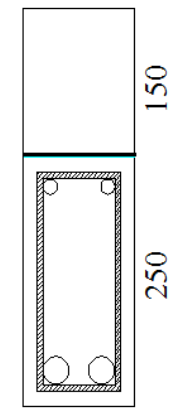

120

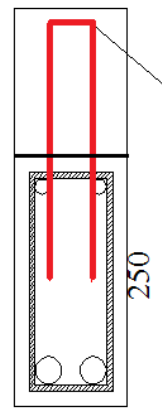

120 ø,3 $\mathrm{mm} \mathrm{c} / 125 \mathrm{~mm}$

$\varnothing 8,0 \mathrm{~mm} \mathrm{c} / 100 \mathrm{~mm}$

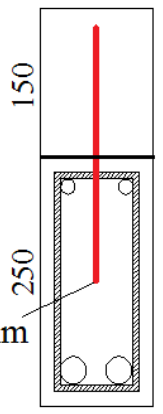

120

(g)

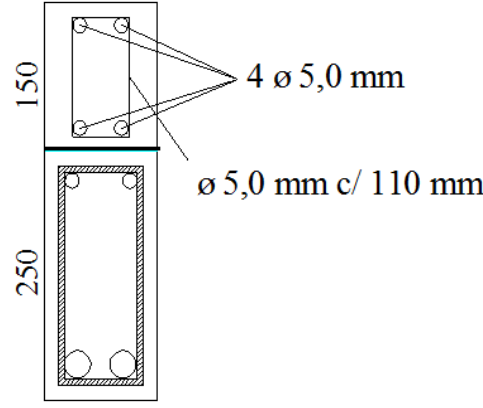

120

(h)

Unidades em " $m$ "

Figura 3: Seção transversal e detalhamento das vigas: (a) VM25 e todas as vigas antes do reforço; (b) VM40; (c) VRAF3; (d) VRI3; (e) VRI1A; (f) VRU3; (g) VRI2A; (h) VRI1B e VRI1C. 
Tabela 2: Características dos conectores de cisalhamento utilizados

\begin{tabular}{c|l|c|c|c|c|c} 
Tipo de conector & \multicolumn{1}{c|}{$\begin{array}{c}\emptyset_{\mathrm{c}} \\
(\mathrm{mm})\end{array}$} & \multicolumn{2}{|c|}{$\begin{array}{c}\mathrm{a}_{\mathrm{sc}} \\
\left(\mathrm{cm}^{2} / \mathrm{m}\right)\end{array}$} & $\begin{array}{c}\mathrm{L}_{\text {sub }} \\
(\mathrm{cm})\end{array}$ & $\begin{array}{c}\mathrm{L}_{\mathrm{ref}} \\
(\mathrm{cm})\end{array}$ \\
\hline "AF" & 8.0 a cada $10 \mathrm{~cm}$ & 5,0 & - & - & 7,0 & 3,5 \\
\hline "U" & 6.3 a cada $12,5 \mathrm{~cm}$ & 5,0 & - & - & 12,5 & 13,5 \\
\hline "I" & $8.0 \mathrm{c} /$ espaçamento variável & 5,0 & 1,25 & 0,0 & 12,5 & 13,5 \\
\hline
\end{tabular}

Legenda:

$\emptyset_{c}=$ diâmetro do conector

$a_{s c}=$ área de aço dos conectores

$L_{\text {sub }}=$ comprimento do trecho do conector inserido dentro do substrato

$L_{\text {ref }}=$ comprimento do trecho do conector inserido dentro do reforço

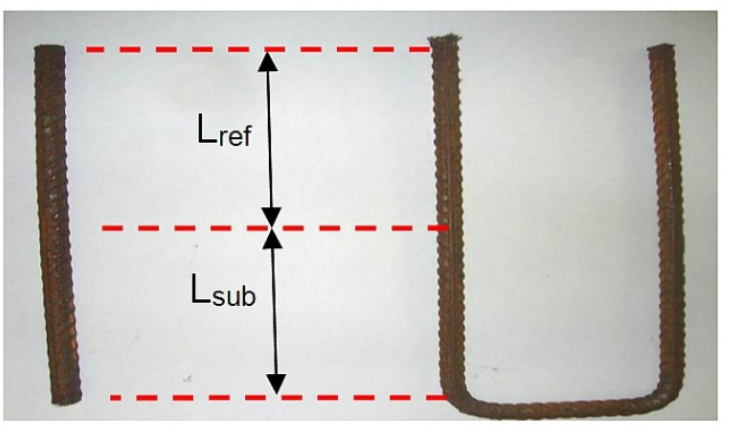

(a) Conector I

(b) Conector U

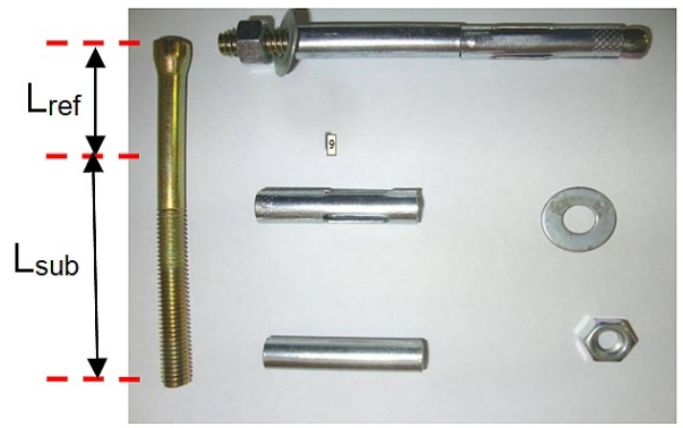

(c) Conector AF

Figura 4: Fotos detalhadas dos conectores de cisalhamento utilizados $\left(\mathrm{a}_{\mathrm{sc}}\right)$

$\mathrm{Na} 2^{a}$ série foram ensaiadas seis vigas (VRI1A, VRI1B, VRI1C, VRI2A, VRI2B e VRI2C), todas reforçadas. Quatro estavam pré-fissuradas antes da execução do reforço, e duas não utilizaram armadura para confinar o concreto adicionado à face comprimida. Estas peças também se diferenciavam em função das áreas de aço de conectores de cisalhamento tipo "I" utilizada, que foram de $a_{\mathrm{sc}}$ igual a: $5 \mathrm{~cm}^{2} / \mathrm{m}$, a $1,25 \mathrm{~cm}^{2} / \mathrm{m}$ ou sem $\mathrm{a}_{\mathrm{sc}}$.

Para reforçar as vigas, inicialmente fez-se a escarificação manual da face comprimida usando-se ponteira e martelo, e fez-se os furos para fixar os conectores de cisalhamento com furadeira elétrica. Em seguida, a superfície rugosa foi limpa e escovada para remover todo pó e material solto e os conectores de cisalhamento foram fixados preenchendo-se os furos com resina epóxi, conforme ilustra a Figura 5. Logo após, posicionava-se a armadura de confinamento na face comprimida das peças que possuíam esta armadura, e procedia-se a concretagem da camada de $150 \mathrm{~mm}$ de espessura do reforço.

As vigas VRI1B, VRI2B, VRI1C e VRI2C foram colocadas no pórtico de reação e carregadas antes de executar o reforço até próximo da carga de escoamento da armadura longitudinal de tração para gerar uma préfissuração. Desta forma era possível avaliar a influência deste parâmetro na resistência final. Em seguida, tais peças foram descarregadas e só então o reforço foi executado.
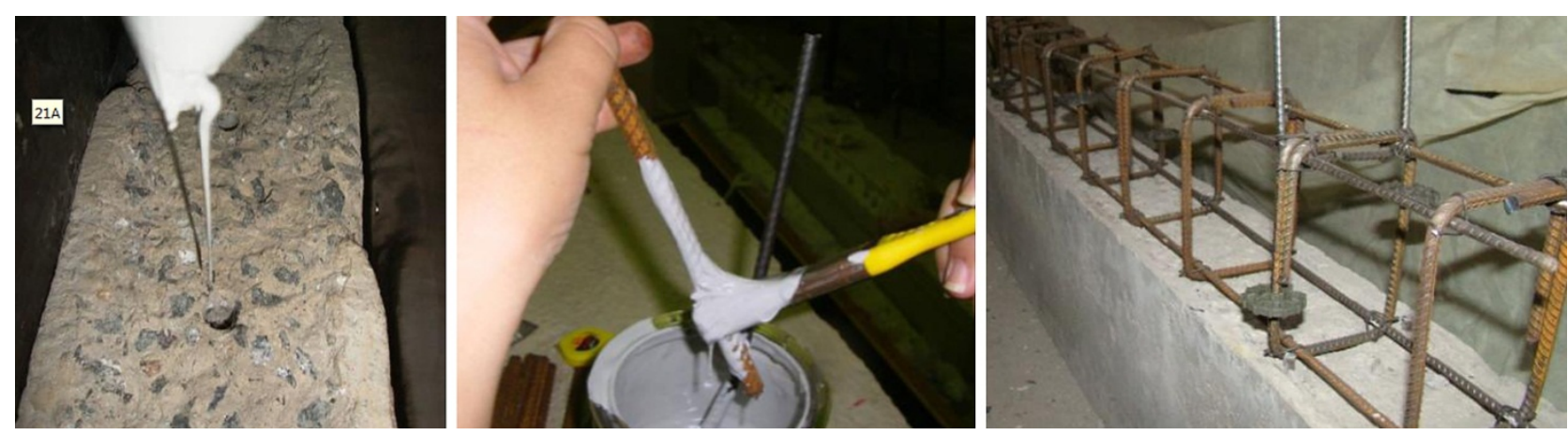

Figura 5: (a) aspecto da superfície escarificada, (b) aplicação de resina epóxi em um conector "I",

(c) armadura de confinamento posicionada em uma viga. 
Após o concreto do reforço atingir uma resistência à compressão próxima à do substrato, as peças foram posicionadas no pórtico de reação e carregadas até atingir a ruptura, utilizando-se um dos esquemas estáticos ilustrados na Figura 6. Com exceção das vigas VRI1B e VRI1C, nas quais se aplicou duas cargas concentradas equidistantes dos apoios (esquema estático " $b$ "), todas as demais vigas foram ensaiadas aplicando-se uma única carga concentrada no meio do vão (esquema estático “a”). Esta alteração foi utilizada na tentativa de aumentar as tensões tangenciais atuantes na região da junta, e forçar uma eventual ruptura prematura por falhas de aderência entre os concretos do substrato e do reforço.

Para monitorar o comportamento das vigas foram colados extensômetros elétricos para medir as deformações da armadura longitudinal de tração, dos estribos, da armadura de confinamento, dos conectores de cisalhamento, e do concreto. A Figura 7 apresenta a instrumentação, no qual os extensômetros da armadura foram denominados de EA, e os extensômetros do concreto foram denominados de EC. Também foram monitorados os deslocamentos verticais (flechas) e horizontais (deslizamentos ao longo da junta entre substrato e reforço), usando relógios comparadores, conforme indica a Figura 8. Os relógios fixados ao longo da linha pontilhada monitoravam o deslizamento ao longo da junta.

Em casos reais de reforço por encamisamento, os engenheiros geralmente apresentam dificuldades de moldar e adensar o novo concreto devido à falta de acessibilidade ao local do reforço. Em virtude disso, optou-se por utilizar concreto auto-adensável (CAA) com brita " 0 " na confecção do concreto do reforço das vigas estudadas, visto que a avaliação do desempenho deste material em casos de reabilitação de estruturas é extremamente interessante para o meio técnico.
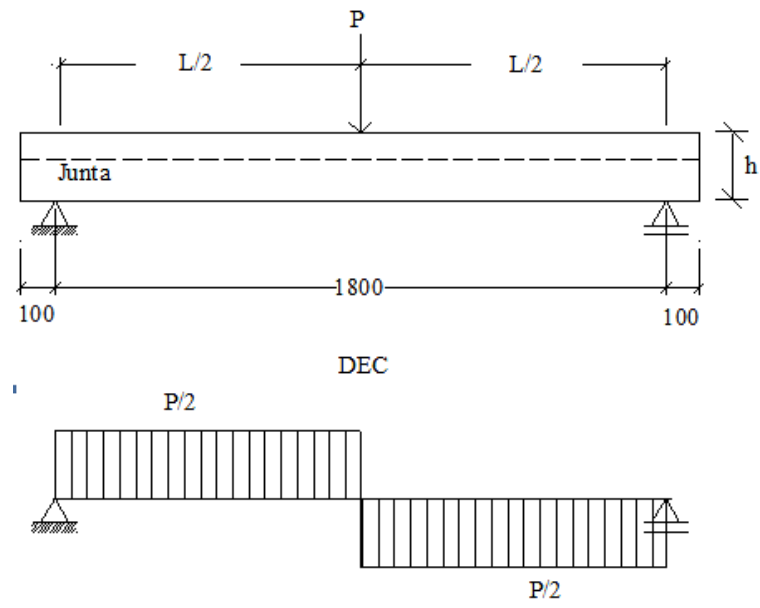

DMF
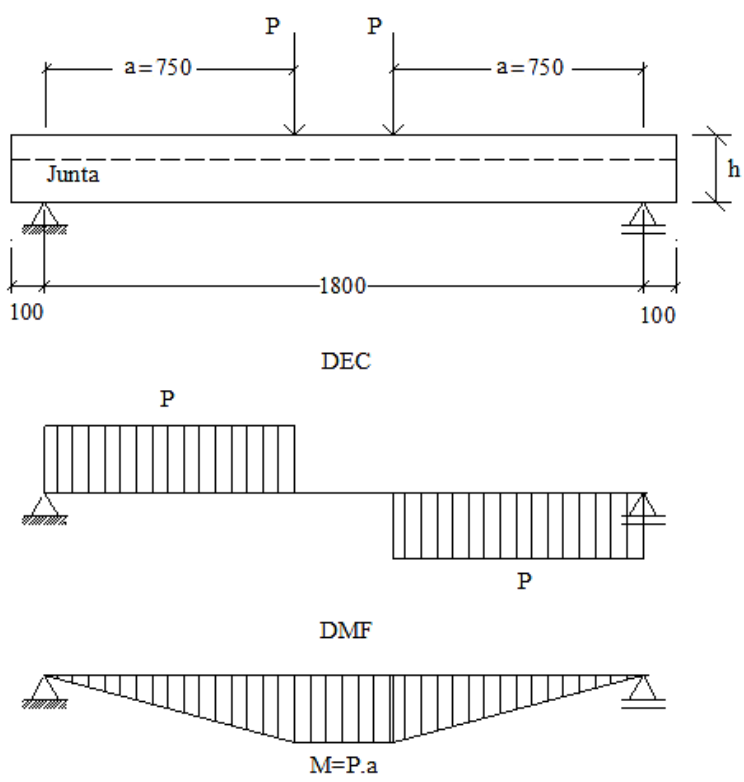

(b) Esquema estático " $b$ "

(a) Esquema estático "a"

de Momento Fletor.

Figura 6: Esquemas estáticos adotados nos ensaios (dimensões em mm).

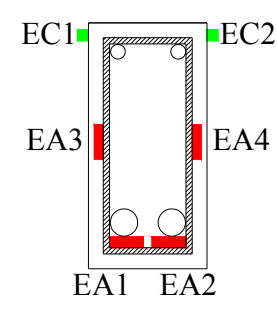

(a) VM25

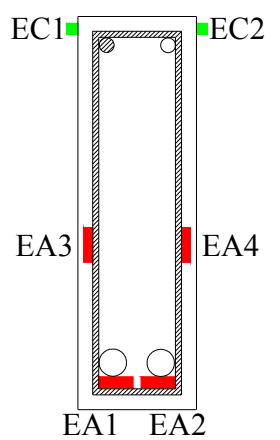

(b) VM40

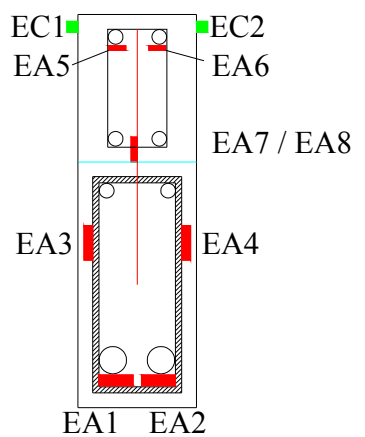

(c) Vigas reforçadas

Figura 7: Posição dos extensômetros na armadura e no concreto. 


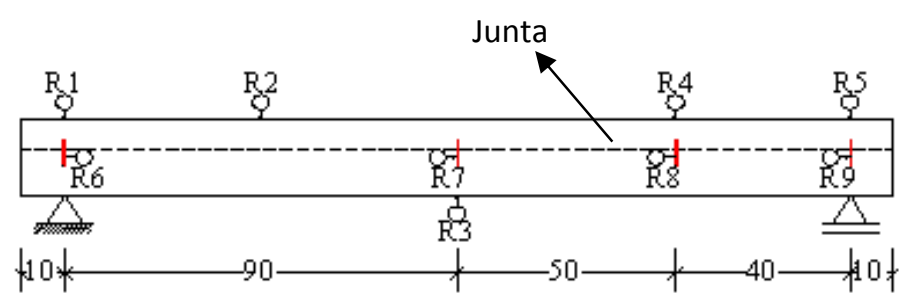

Figura 8: Posição dos relógios digitais comparadores (unidades em cm).

\section{ANÁLISE DOS RESULTADOS}

A resistência à compressão $\left(f_{\mathrm{cj}}\right)$ dos concretos do substrato e do reforço obtidas por corpos-de-prova cilíndricos $15 \mathrm{~cm} \times 30 \mathrm{~cm}$ ensaiados no dia do ensaio das vigas estão na Tabela 3. A evolução dos módulos de elasticidade em função da idade do concreto, também obtida por corpos-de-prova, está ilustrada na Figura 9.

Comparando os resultados desta tabela com os deste gráfico percebe-se que apesar das vigas apresentarem diferenças de resistência à compressão entre os concretos do reforço e do substrato, os módulos de elasticidade de ambos os materiais eram próximos. Portanto, constata-se que o uso do CAA com brita "0" para executar esta intervenção trouxe vantagens porque se minimizava a probabilidade de surgirem deformações diferenciais na região da junta, e consequentemente, minimizava-se o aparecimento de fissuras horizontais neste local. Além disso, o CAA por ser um material que possui alto teor de finos, provavelmente proporcionou uma melhor aderência ao concreto do substrato.

\begin{tabular}{|c|c|c|c|c|c|c|c|}
\hline \multirow{2}{*}{ Série } & \multirow{2}{*}{ Peça } & \multicolumn{2}{|c|}{ Idade no ensaio (dias) } & \multicolumn{2}{|c|}{$\mathrm{f}_{\mathrm{cj}}(\mathrm{MPa})$} & \multicolumn{2}{|c|}{ Traço } \\
\hline & & Substrato & Reforço & Substrato & Reforço & Substrato & Reforço \\
\hline \multirow{5}{*}{ 1a } & VM25 & 182 & - & 39,8 & - & $\mathrm{T} 1$ & - \\
\hline & VR3I & 179 & 79 & 39,7 & 45,4 & $\mathrm{~T} 1$ & $\mathrm{~T} 2$ \\
\hline & VR3U & 186 & 86 & 39,9 & 45,7 & $\mathrm{~T} 1$ & $\mathrm{~T} 2$ \\
\hline & VRAF & 186 & 86 & 39,9 & 45,7 & T1 & $\mathrm{T} 2$ \\
\hline & VM40 & 184 & - & 39,8 & - & $\mathrm{T} 1$ & - \\
\hline \multirow{6}{*}{$2 \underline{a}$} & VRI1A & 359 & 53 & 42,8 & 41,3 & T1 & $\mathrm{T} 1 \mathrm{~B}$ \\
\hline & VRI2A & 358 & 52 & 42,8 & 41,2 & T1 & $\mathrm{T} 1 \mathrm{~B}$ \\
\hline & VRI2B & 360 & 54 & 42,8 & 41,3 & $\mathrm{~T} 1$ & $\mathrm{~T} 1 \mathrm{~B}$ \\
\hline & VRI1B & 357 & 51 & 49,4 & 41,1 & $\mathrm{~T} 1 \mathrm{~A}$ & $\mathrm{~T} 1 \mathrm{~B}$ \\
\hline & VRI1C & 360 & 54 & 49,4 & 41,3 & T1A & T1B \\
\hline & VRI2C & 361 & 55 & 49,4 & 41,4 & T1A & T1B \\
\hline \multicolumn{8}{|c|}{$\begin{array}{r}\text { Obs.: Tipos de traços: T1 refere-se } \\
\text { T2 refere-se } \\
\text { T1A refere-se } \\
\text { T1B refere-se }\end{array}$} \\
\hline
\end{tabular}




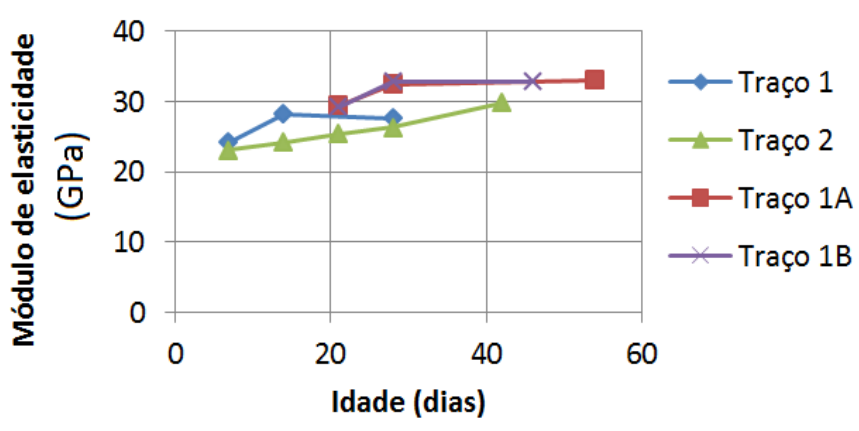

Figura 9: Evolução do módulo de elasticidade x idade para os traços usados.

A Tabela 4 apresenta o modo de ruptura das vigas ensaiadas, o momento atuante no instante da ruptura $\left(\mathrm{M}_{\mathrm{u}}\right)$ e a relação entre os momentos de ruptura das vigas reforçadas e das vigas monolíticas VM25 e VM40. Optou-se por apresentar o valor do momento e não da força última aplicada, pois como foram usados dois esquemas de ensaio distintos, não seria possível compara diretamente os valores das forças de ruptura entre as peças. Contudo, pelo fato das peças terem sido dimensionadas para romper por escoamento da armadura tracionada, todas deveriam romper teoricamente para o mesmo valor de momento fletor atuante, independentemente da posição da carga aplicada. Logo, considerou-se aceitável a comparação da resistência da peça usando o momento fletor.

\begin{tabular}{|c|c|c|c|c|}
\hline Peça & $\begin{array}{c}\mathrm{M}_{\mathrm{u}} \\
\text { (kN.m) }\end{array}$ & $M_{u} / M_{u ~ v M 25}$ & $M_{u} / M_{u ~ v M 40}$ & Modo de ruptura \\
\hline VM25 & 54,0 & - & - & Escoamento do aço tracionado \\
\hline VM40 & 96,3 & 1,8 & - & Escoamento do aço tracionado \\
\hline VRI3 & 111,6 & 2,1 & 1,2 & Escoamento do aço tracionado \\
\hline VRU3 & 101,3 & 2,0 & 1,1 & Perda parcial de aderência e escoamento do aço \\
\hline VRAF3 & 108,0 & 2,0 & 1,1 & Perda parcial de aderência e escoamento do aço \\
\hline VRI1A & 76,5 & 1,4 & 0,8 & Perda parcial de aderência e escoamento do aço \\
\hline VRI1B & 110,0 & 2,0 & 1,1 & Perda parcial de aderência e escoamento do aço \\
\hline VRI1C & 102,0 & 1,9 & 1,1 & Perda parcial de aderência e escoamento do aço \\
\hline VRI2A & 99,0 & 1,8 & 1,0 & Escoamento do aço tracionado \\
\hline VRI2B & 108,0 & 2,0 & 1,1 & Escoamento do aço tracionado \\
\hline VRI2C & 102,0 & 1,9 & 1,1 & Escoamento do aço tracionado \\
\hline
\end{tabular}

Pela Tabela 4 percebe-se que todas as vigas reforçadas apresentaram aumento real de capacidade portante em relação à viga VM25, que representava a viga antes da execução da reabilitação. A maioria das vigas reforçadas praticamente dobrou de resistência, a única exceção foi a viga VRI1A, na qual o aumento da resistência foi de apenas $40 \%$. Isso provavelmente ocorreu porque a VRI1A não utilizava conectores de cisalhamento nem armadura de confinamento, o que prejudicou seu monolitismo, e permitiu a ocorrência de uma ruptura prematura por perda parcial de aderência ao longo da junta.

Os resultados indicaram que, com exceção da viga VRI1A, todas as demais apresentaram capacidades portante superiores a da viga VM40, indicando que as peças reforçadas realmente trabalharam como se fossem peças monolíticas mesmo depois de passarem pela intervenção apresentada neste trabalho.

Os resultados dos ensaios das vigas reforçadas da 1a série indicaram que o conector tipo "I" foi o mais eficiente para impedir a perda de aderência entre o concreto do substrato e o concreto do reforço. Isso porque as vigas VRU3 e VRAF3, executadas usando conectores tipo " $U$ " e "AF", apresentaram indícios de desplacamento entre o concreto do reforço e do substrato aproximadamente à $1 / 4$ do vão. Já a viga VRI3, que usava conector tipo "I", não apresentou nenhuma fissura na região da junta, sugerindo que este conector conseguiu impedir o deslizamento entre estes dois 
matérias. A Figura 10 apresenta o esquema de fissuração de algumas vigas, e a elipse vermelha indica o local em que ocorreu o desplacamento localizado entre os concretos do substrato e do reforço.

Constatado que o conector "I" era o mais eficiente, este foi utilizado nas vigas da 2 a série de ensaios. Nesta série, foi analisada a influência da taxa de conectores na resistência ao cisalhamento da junta entre concreto novo e concreto antigo.

As fissuras horizontais que indicavam perda parcial da aderência entre os concretos só surgiram nas vigas que não tinham conectores de cisalhamento tipo "I" $\left(\mathrm{a}_{\mathrm{sc}}=0,0 \mathrm{~cm}^{2} / \mathrm{m}\right)$, ou nas peças que usavam outros tipos de conectores de cisalhamento (conectores "AF" e "U"). No caso das peças que usaram conector tipo "I", as que apresentaram maior perda parcial da aderência foram as VR1A, VRI1B e VRI1C, indicando que a ausência da armadura de costura coloca em risco o desempenho da peça reabilitada, uma vez que existe a possibilidade de ocorrer ruptura prematura na região da junta.

Entretanto, comparando-se a VRI1A com as vigas VRI1B e VRI1C, que não tinham conectores de cisalhamento, mas que possuíam armadura de confinamento, percebeu-se a que a armadura de confinamento foi essencial para o bom funcionamento da intervenção analisada. Acredita-se que esta armadura tenha, de alguma forma, retardado o aparecimento das fissuras na região da junta, fazendo com que a capacidade portante não fosse muito prejudicada porque a perda de aderência das vigas VRI1B e VRI1C ocorreu praticamente ao mesmo tempo em que a armadura longitudinal iniciava seu escoamento. De qualquer forma, este fato confirma a importância do tipo e da taxa de conector usado no projeto do reforço para garantir uma boa monoliticidade da estrutura reabilitada.

No caso deste trabalho, percebeu-se que ao acrescentar uma camada de $150 \mathrm{~mm}$ de concreto à face comprimida de uma viga, gerando um aumento de $60 \%$ na altura de sua seção transversal, o ganho de resistência ao momento fletor obtido foi de praticamente $100 \%$. Entretanto, para obter este ganho de resistência foi preciso garantir a monoliticidade das peças após a intervenção utilizando tanto uma armadura de confinamento na camada de concreto adicionada, quanto uma armadura de costura (conectores de cisalhamento) para melhorair a transferência de esforço entre o concreto novo e o concreto antigo da peça.

As deformações do aço e do concreto obtidas pelos extensômetros confirmaram o escoamento das barras de aço tracionadas (ver Figura 11) e mostraram que o concreto da fibra mais comprimida não chegou a esmagar (ver Figura 12), confirmando os modos de ruptura observados visualmente nos ensaios.

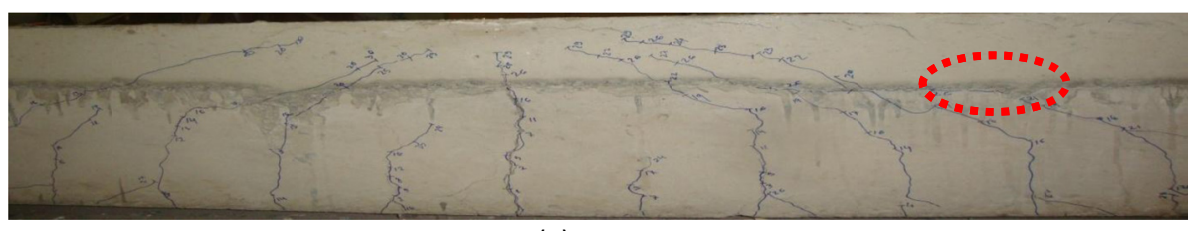

(a) VRAF3

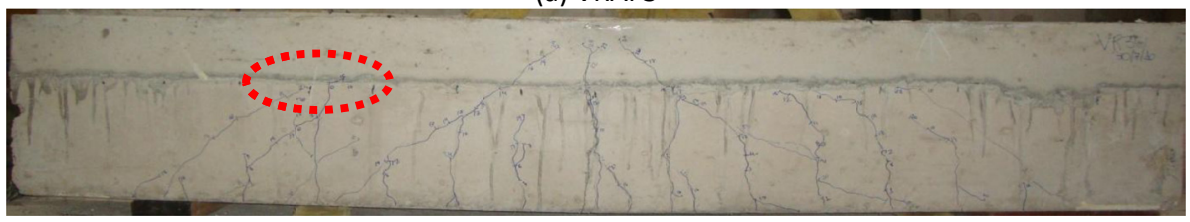

(b) VRU3

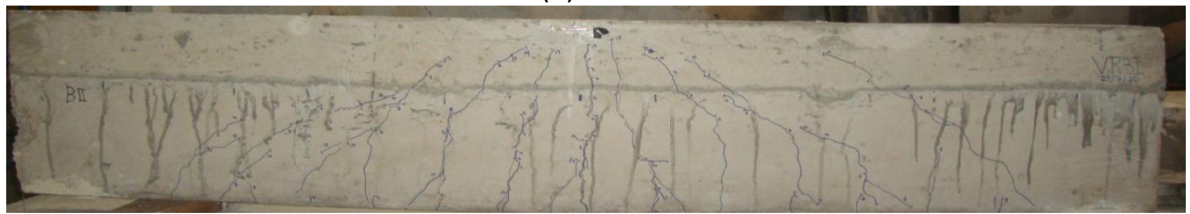

(c) VRI3

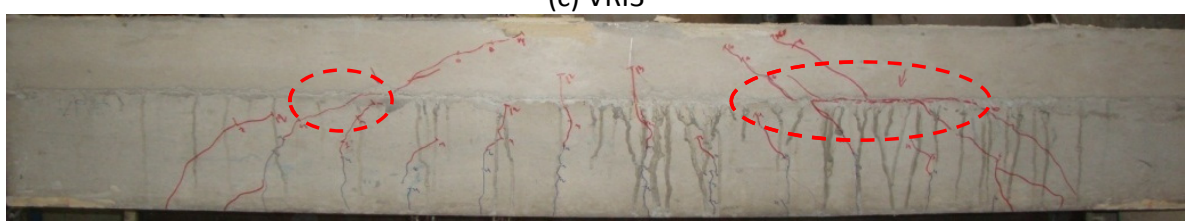

(d) VRI1C

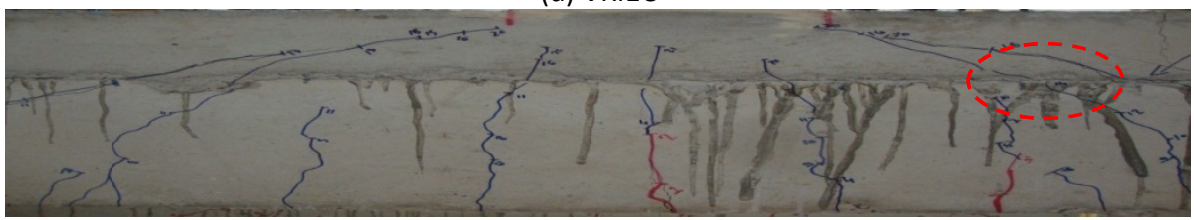

(e) VRI1A

Figura 10: Esquema de fissuração de alguma das vigas ensaiadas. 


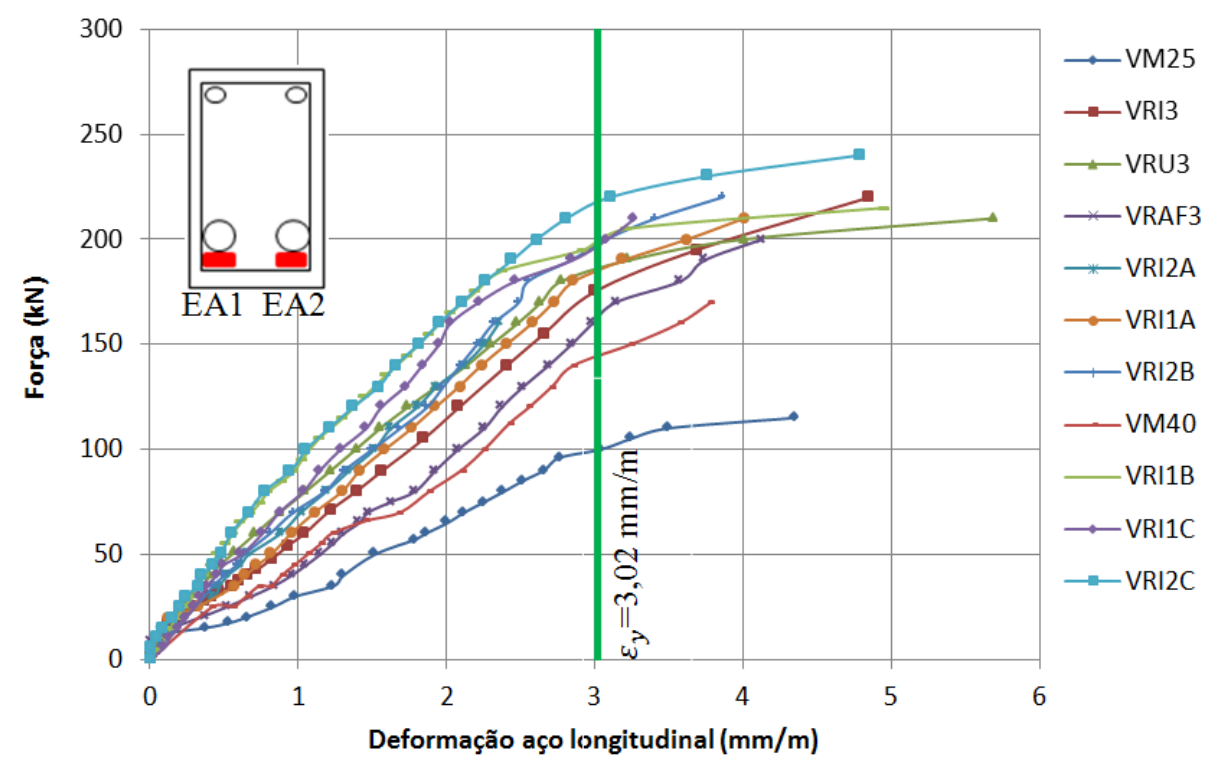

Figura 11: Diagrama força $x$ deformação da armadura longitudinal de tração

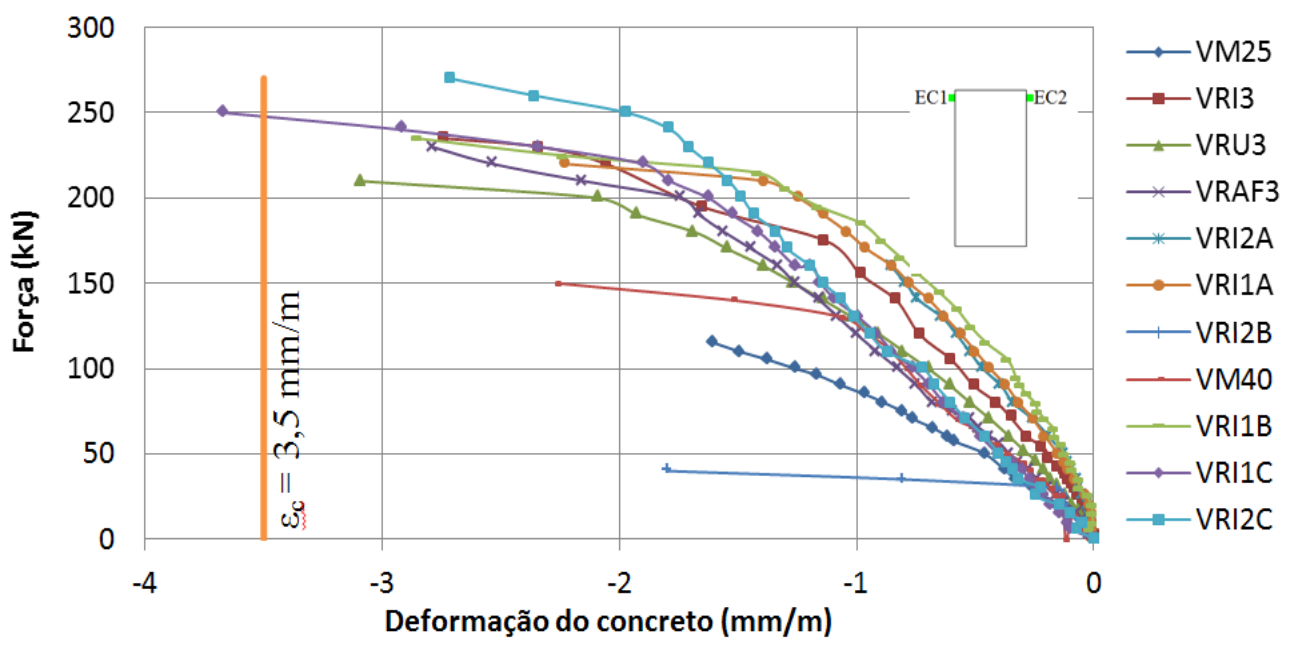

Figura 12: Diagrama força $x$ deformação do concreto comprimido

\section{CONCLUSÕES}

- Todas as vigas reforçadas apresentaram aumento de capacidade portante em relação à viga antes do reforço, sendo que a maioria praticamente dobrou de resistência após a intervenção. Isso indica que a adição de uma certa espessura de concreto à face comprimida pode proporcionar aumentos significativos na resistência ao momento fletor de vigas de concreto armado.

- Praticamente em todas as vigas reforçadas que possuíam conectores e armadura de confinamento, mesmo naquelas que estavam pré-fissuradas antes da reabilitação, a capacidade portante foi próxima à de uma peça monolítica de mesma seção transversal. A única peça que não teve comportamento satisfatório foi justamente a que não possuía nem conector nem armadura de confinamento. Isso sugere a importância de se dimensionar corretamente estes dois tipos de
- armadura para garantir o monolitismo da peça e o bom desempenho da técnica de reforço aqui apresentada.

- A boa transferência de esforço de cisalhamento ao longo da junta depende de uma série de fatores, dentre eles, do tipo de conector de cisalhamento usado e da posição do mesmo dentro da seção transversal da peça. No caso deste estudo, dentre os três conectores estudados, o mais eficaz experimentalmente foi o conector do tipo "I" pois evitou o surgimento de fissuras ao longo da ligação entre concreto novo e antigo. Isso indica que ainda são necessários mais estudos para avaliar quais características são desejáveis para tal conector, a fim de garantir boa aderência entre concretos moldados em idades distintas.

- Os ensaios realizados indicaram ser interessante fazer uma análise dos locais em que estes conectores de cisalhamento devem ser colocados ao 
longo das peças reforçadas, para que sua contribuição na resistência seja mais bem aproveitada. Para o caso em estudo, o ideal talvez fosse colocar um maior número de conectores próximos de $1 / 4$ do vão da viga, pois foi justamente nesta região que iniciava o desplacamento entre os concretos.

- As vigas pré-fissuradas não apresentaram perda de capacidade portante significativa em relação às vigas íntegras, indicando que se a abertura das fissuras pré-existentes estiver dentro dos limites aceitáveis de norma, o vedamento destas antes do reforço não é necessariamente obrigatório. Entretanto, caso as aberturas sejam elevadas, é essencial fechá-las para garantir a durabilidade da peça. Também é importante lembrar que a intensidade de fissuração interfere na rigidez da peça e, consequentemente, deve ser considerada no projeto do reforço para que a estrutura reabilitada não atinja nenhum Estado Limite de Serviço antes do previsto.

- O uso de concreto auto-adensável (CAA) como material de reforço mostrou ser bastante vantajoso, pois não se observou nenhum tipo de falha de concretagem nas vigas estudadas, apesar da dificuldade de acesso ao local. Além disso, seu uso facilitou os processos de moldagem e adensamento do concreto do reforço, pois eliminava o uso de vibradores de imersão. Constatou-se também que a aderência do CAA ao substrato foi muito boa, uma vez que, mesmo nas peças reforçadas sem uso de nenhum conector de cisalhamento, a junta não apresentou fissuração significativa até próximo do momento fletor de ruptura previsto para a estrutura.

\section{AGRADECIMENTOS}

Os autores agradecem a CAPES e ao CNPq pelo financiamento concedido, e às empresas Carlos Campos Consultoria, Impercia e Realmix, pela doação de materiais e apoio técnico prestado na execução dos ensaios.

\section{REFERÊNCIAS BIBLIOGRÁFICAS}

ASSOCIAÇÃO BRASILEIRA DE NORMAS TÉCNICAS (2003). NBR 6118 - Projeto de Estruturas de Concreto. Rio de Janeiro.

HELENE, P. R. L. (1992). Manual para Reparo, Reforço e Proteção de Estruturas de Concreto. São Paulo, Pini.

RISSO, M. A. C. (2008) Resistência ao cisalhamento de ligações de concreto de diferentes idades providas de chumbadores de expansão. Rio de Janeiro. Dissertação (Mestrado). Universidade Federal do Rio de Janeiro-COPPE.
SILVA, P. M. (2011) Avaliação da eficiência do uso de conectores de cisalhamento no reforço de vigas de concreto armado pela face comprimida. Goiânia. Dissertação (Mestrado). Escola de Engenharia Civil da Universidade Federal de Goiás.

SAHB, K. F. P. (2008) Análise experimental de pilares de concreto armado submetidos à flexo-compressão e reforçados com concreto auto-adensável e chumbadores. Goiânia. Dissertação (Mestrado). Escola de Engenharia Civil da Universidade Federal de Goiás.

SANTOS, E. W. F. (2006). Reforço de vigas de concreto armado à flexão por ensamisamento parcial. Rio de Janeiro. Dissertação (mestrado). COPPE/UFRJ. Universidade Federal do Rio de Janeiro. 